\title{
Naringenin Inhibits Neointimal Hyperplasia Following Arterial Reconstruction With Interpositional Vein Graft
}

\author{
Cenk Cayci, MD, * Trevor C. Wahlquist, BS, † Serin I. Seckin, BS, † Vefa Ozcan, MD, $\neq$ Ayse B. Tekinay, PhD, $\$$ \\ Timothy P. Martens, MD, † Mehmet C. Oz, MD, † and Jeffrey A. Ascherman, MD\|
}

\begin{abstract}
Vessels respond to injury by a healing process that includes the development of neointima. Stenosis secondary to neointima formation is the main cause of failure following arterial reconstructions. Vessel wall homeostasis is regulated by proinflammatory cytokines that affect smooth muscle cell proliferation, growth, migration, and death. We assessed the hypothesis that naringenin, a flavinoid possessing anti-inflammatory, antioxidant, and antiproliferative activities, reduces neointimal hyperplasia (NIH) following vascular injury.
\end{abstract}

Arterial injury was created by interposition grafting of autologous right superficial epigastric vein graft into the right femoral artery (FA) in 48 male Sprague-Dawley rats. Following injury, the rats were divided into 4 groups $(\mathrm{n}=12)$. Two groups were treated with naringenin $(100 \mathrm{mg} / \mathrm{kg}$ intraperitoneal q daily) for 2 and 4 weeks each while 2 control groups received normal saline for the same durations. For Sham group $(n=10)$, the FA and vein were isolated without any additional procedure. Rats were killed at the end of treatment regimen in all groups, and FAs were harvested. Thickness of intima was measured in histologic sections, and levels of platelet derived growth factor (PDGF)-BB, TNF $\alpha$, and Ki67 labeling index (Ki67 LI) were quantified in immunohistochemical analyses to assess the amount of NIH and mechanisms underlying its formation.

Although there was no significant difference between the groups at 2 weeks, neointima thickness was lower in the naringenin treated group at 4 weeks $(23.7 \pm 2.3$ vs. $35.6 \pm 2.6 \mu \mathrm{m}$ in control group; $P<0.001)$. The levels of PDGF-BB, and TNF $\alpha$ were lower in naringenin treated groups at both 2 weeks (PDGF-BB [0.21\% $\pm 0.03 \%$ versus $0.39 \% \pm 0.05 \%$ in control group, $P<0.001), \mathrm{TNF} \alpha(21.2 \% \pm 0.8 \%$ vs. $36.1 \% \pm 1.9 \%$ in control group, $P<0.001]$ ) and 4 weeks (PDGF-BB $[0.25 \% \pm 0.03 \%$ vs. $0.57 \% \pm$ $0.09 \%$ in control group, $P<0.001]$, TNF $\alpha[25.5 \% \pm 1.8 \%$ vs. $45.0 \% \pm$ $2.9 \%$ in control group, $P<0.001]$ ). Ki67 LI was lower in naringenin treated groups at 2 weeks $(13.9 \% \pm 2.8 \%$ vs. $18.7 \% \pm 3.7 \%$ in control group, $P<$ $0.05)$, and at 4 weeks $(17.5 \% \pm 2.6 \%$ vs. $31.1 \% \pm 4.7 \%$ in control group, $P<0.001$ ), indicating a lower level of cellular proliferation.

Naringenin reduces NIH following arterial reconstruction. This may be mediated by a decrease in PDGF-BB and TNF $\alpha$ levels and the resulting down-regulation of smooth muscle cells' migration and proliferation.

Received April 13, 2008, and accepted for publication, after revision, December 19, 2008.

From the *Department of Surgery, NYPH-Weill Cornel Medical College; $†$ Division of Cardiothoracic Surgery, Department of Surgery, NYPH-Columbia University Medical Center, New York, NY; †Department of Cardiovascular Surgery, Pamukkale University, Denizli, Turkey; §Laboratory of Molecular Biology, Howard Hughes Medical Institute, The Rockefeller University, New York, NY; IInstitute of Materials Science and Nanotechnology, Bilkent University, Ankara, Turkey; and \|Division of Plastic Surgery, Department of Surgery, NYPH-Columbia University Medical Center, New York, NY.

Paper presented at the Plastic Surgery Research Council 52nd Annual Meeting June-2007, Stanford CA, and the abstract was published in the supplement edition of PRS journal.

Reprints: Jeffrey A. Ascherman, MD, Columbia University Medical Center, 161 Fort Washington Ave-Suite 607, New York, NY 10032. E-mail: jaa7@columbia.edu.

Copyright (C) 2009 by Lippincott Williams \& Wilkins

ISSN: 0148-7043/10/6401-0105

DOI: $10.1097 / \mathrm{SAP} .0 \mathrm{~b} 013 \mathrm{e} 31819 \mathrm{~b} 03 \mathrm{~cd}$
Key Words: naringenin, neointimal hyperplasia, arterial reconstruction with interpositional vein graft

(Ann Plast Surg 2010;64: 105-113)

$D^{\mathrm{o}}$ evelopment of neointima as a part of the healing process in response to injury is the main reason of failure in arterial reconstruction. The incidence of this outcome is as high as $15 \% 1$ year after, ${ }^{1}$ and $44 \% 10$ years after ${ }^{2}$ aortocoronary bypass grafting with autologous saphenous vein grafting. Intimal thickening and luminal narrowing are also a major cause of failure after coronary angioplasty, ${ }^{3}$ femoropopliteal revascularization with autologous saphenous vein or synthetic grafts or transluminal angioplasty., Recent advances in the understanding of their biology suggest that endothelial cells play a central role in the development of intimal hyperplastic response after arterial reconstruction.

The healing process in an arterial reconstruction with a vein graft involves responses to both surgical trauma, ${ }^{5,6}$ and adaptation of the vein to arterial hemodynamic conditions. ${ }^{7}$

Among several pro-inflammatory cytokines with possible roles in neointimal hyperplasia, platelet derived growth factor (PDGF) has diverse effects on different target cells, and has been implicated in the pathogenesis of arterial vascular disease. ${ }^{8}$ Tumor necrosis factor-alpha $(\mathrm{TNF} \alpha)$, another proinflammatory cytokine, is locally generated from arterial smooth muscle cells following vascular trauma and is implicated in the pathogenesis of vein graft neointimal hyperplasia.9,10

Flavinoids are found in seeds, citrus fruits, olive oil, tea, and red wine and are commonly consumed within the human diet ${ }^{11}$ in small amounts (approximately $1 \mathrm{~g}$ of flavinoids per day). They have been reported by many authors to have anti-inflammatory, antiallergic, antiviral, and antioxidant effects, and they have also shown the ability to inhibit tumor cell proliferation. ${ }^{12,13}$ Because of the pivotal role of anti-inflammatory medications, researchers ${ }^{14-16}$ have attempted to identify naturally-occurring, novel biologic components from plants with potent anti-inflammatory activity. The inhibitory effects of flavinoids, especially naringenin on $\mathrm{TNF} \alpha$, has been demonstrated in previous studies. ${ }^{17,18}$ It has also been demonstrated that naringenin can exert antifibrogenic affects through TGF- $\beta$ signaling, ${ }^{19}$ which also has a role in the migration of smooth muscle cells into the intima. ${ }^{20-22}$ Considering the activities of naringenin on pro-inflammatory cytokines and the known roles of these cytokines on the development of intimal hyperplasia, we designed this study to examine the influence of naringenin on vein graft intimal hyperplasia.

\section{MATERIALS AND METHODS}

Fifty-eight male Sprague-Dawley adult rats, with an age range of 8 to 10 weeks, were used for the study. The body weights of the rats ranged from 240 to $310 \mathrm{~g}$. Columbia University Institute for Animal Care and Use Committee (IACUC) guidelines for the care and the use of laboratory animals were followed throughout all steps in this study. The rats were divided into 3 as control, experi- 
mental, and sham groups. Two experiment groups were treated with naringenin (100 mg/kg intraperitoneal q daily) for 2 and 4 weeks each, whereas 2 control groups received daily intraperitoneal normal saline injections for the same durations. No treatment was applied to the rats in the sham group. Half of the animals in each (experiment, control, and SHAM) group were killed at 2 weeks and the other half at 4 weeks. The arterial reconstruction model with autologous vein grafting was used for the study. For this purpose superficial epigastric vein was interposed to the femoral artery (Fig. 1).

\section{Surgical Procedure}

The rats were anesthetized with isoflurane (1\%-5\%) inhalation. After induction of the general anesthesia, bilateral groin regions were shaved with electric clippers. An incision was made along the entire length of the right inguinal fold. The lateral aspect of the incision was retracted firmly, drawing the epigastric vessels out in a linear course. The superficial epigastric vein was dissected out from the epigastric fat pad, through its origin from the femoral vein. A $10-\mathrm{mm}$ segment of the superficial epigastric vein was harvested. The remaining epigastric fat pad was dissected and
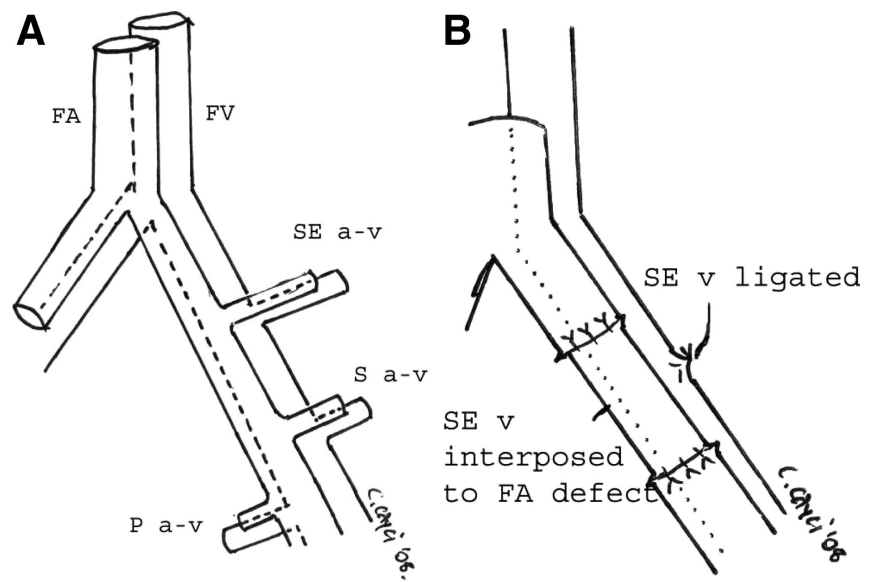

FIGURE 1. A, vascular anatomy of the femoral region; B, Diagram of rat interpositional vein graft model. FA, femoral artery; FV, femoral vein; SE a-v, Superificial epigastric artery and vein; $S$ a-v, Saphenous artery and vein; $P$ a-v, popliteal artery and vein.

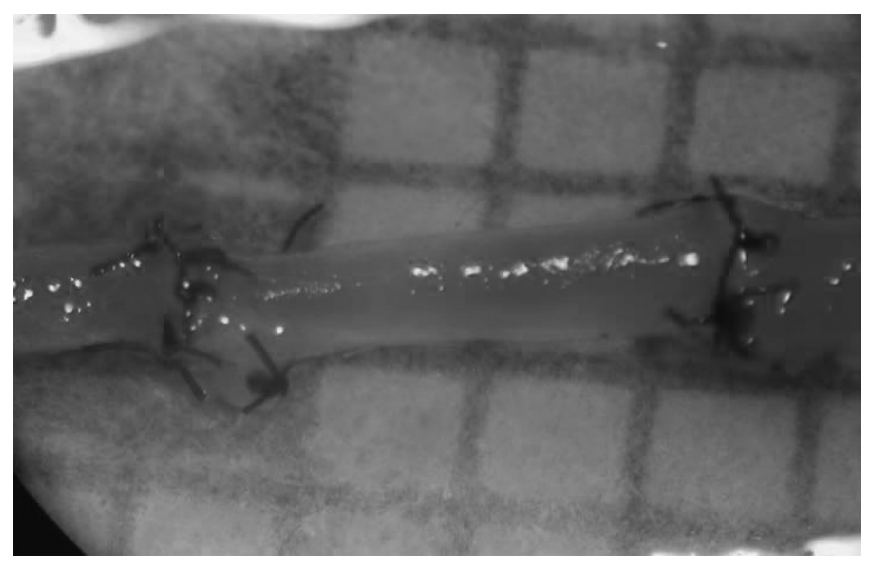

FIGURE 2. Representative photograph showing a completed anastomosis for the interpositional vein graft to the femoral artery. Each square corresponds to $1 \mathrm{~mm}$. Original magnification $\times 16$. retracted laterally, and the femoral neurovascular bundle was exposed. A 15 to $20 \mathrm{~mm}$ tract of the femoral artery (FA), including the superficial epigastric branch, was dissected free from the underlying muscle fascia and femoral vein. The surgical field was irrigated with lidocaine $2 \%$ to minimize vasospasm and a latex membrane was

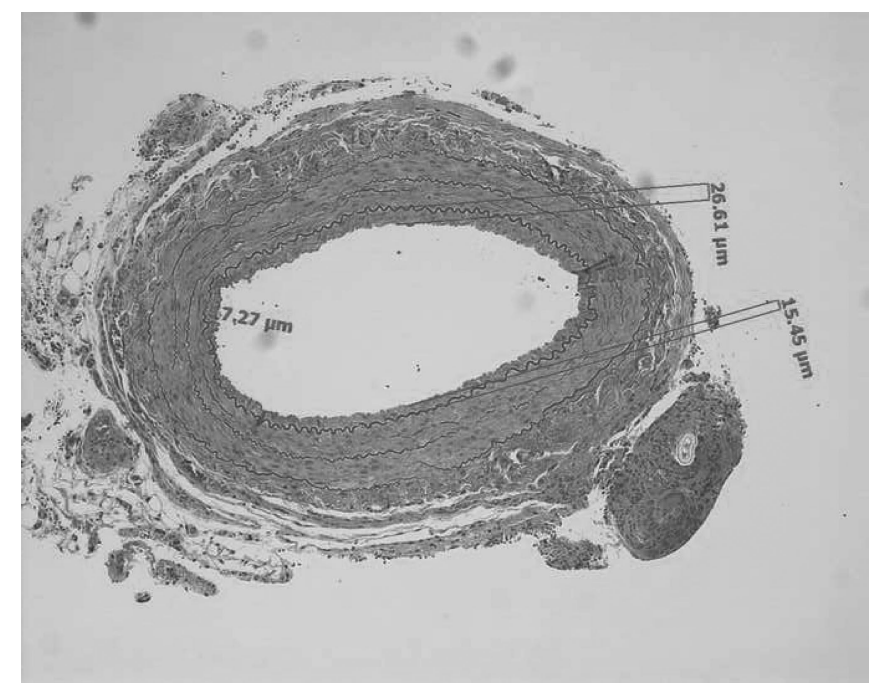

FIGURE 3. Representative light micrographs of cross section of interposed graft (hematoxylin and eosin staining) for intimal thickness measurement. Measurements are done by using the software AxioVision Version 3.1 (Carl Zeiss) in 4 different quadrants and a mean value is obtained for each vessel. Original magnification $\times 100$.
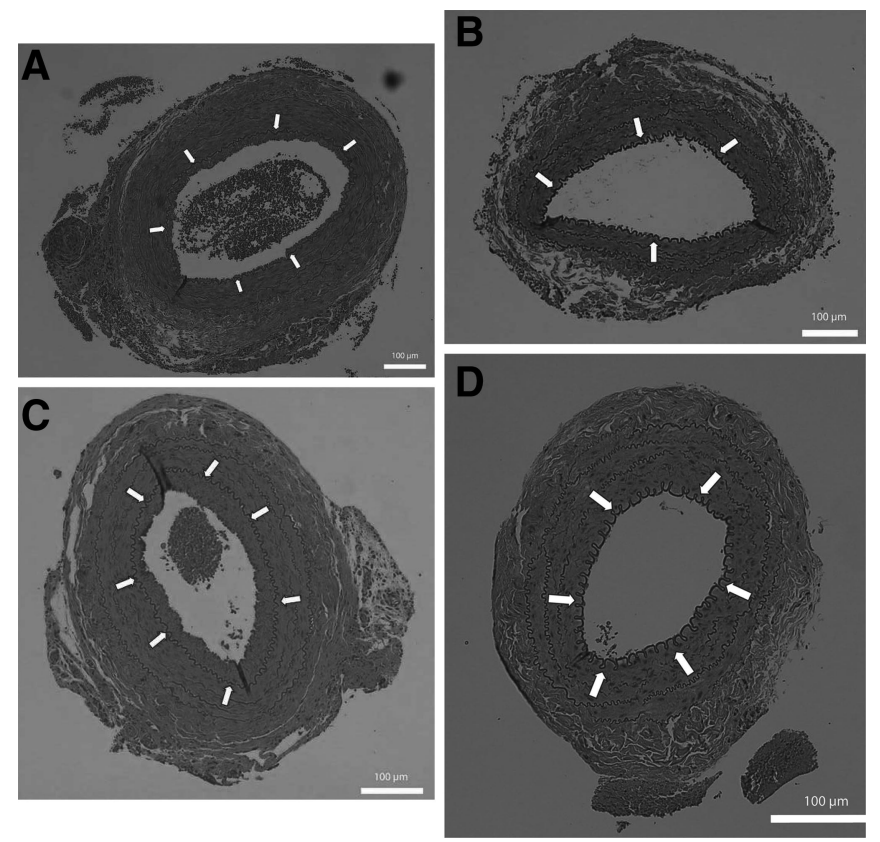

FIGURE 4. Representative light micrographs of cross section of interposed graft (hematoxylin and eosin staining). A, Control group at 2 weeks. B, Naringenin group at 2 weeks. C, Control group at 4 weeks. D, Naringenin group at 4 weeks. White arrows indicate internal elastic membrane. Bar represents $100 \mu \mathrm{m}$. Original magnification $\times 100$. 
positioned beneath the vessels. In the control and experimental groups $(n=48)$, after the proper set-up, the microvascular approximator clamp (vein approximator clamp $0.4 \mathrm{~g} / \mathrm{mm}^{2}$; S\&T Marketing LTD, Neuhausen, Switzerland) was positioned on the FA. A 5 to 7 $\mathrm{mm}$ segment of the FA, including the origin of superficial epigastric artery, was resected. The $10-\mathrm{mm}$ vein graft was interposed to the defect on FA. A standard end-to-end anastomoses as described by Ackland $^{23}$ was performed with 10-0 monofilament nylon suture material (S\&T Marketing LTD), under the magnification of an OPMI-1 Carl Zeiss operating microscope (Carl Zeiss Inc, Oberkochen, Germany) (Fig. 2). In the remaining 10 rats, to serve as the Sham groups, with the same surgical exposure right femoral neurovascular bundle was isolated, the femoral artery and vein are dissected free from the surrounding soft tissues and each other. The skin incision was closed primarily without any additional manipulation to the vascular structures.

Naringenin was purchased from Sigma-Aldrich, Milwaukee, WI (T66001). It was dissolved in dimethyl sulfoxide (DMSO; $\left.10^{-2} \mathrm{M}\right){ }^{24}$

\section{Arterial Harvest and Morphometric Analysis}

Rats were euthanized 2 and 4 weeks post injury. During the harvesting procedure the patency of the vessels were checked by the milking technique as described by Ackland, and recorded. Bilateral femoral artery segments approximately $1 \mathrm{~cm}$ in length were harvested, rinsed with saline, and fixed in 4\% paraformaldehyde for 24 hours. The specimens were then paraffin embedded and 5 - $\mu$ m thick sections were obtained from the middle portion of the interposed vein graft, in an equal distance from the anastomosis site in an effort to eliminate the selection bias. The sections were stained with hematoxylin and eosin. The intimal thickness was measured using AxioVision version 3.1 (Carl Zeiss).

To evaluate the effect of naringenin on intimal thickness, the vessel section was divided into 4 quadrants and, the greatest perpendicular distance between the edge of the inner layer of smooth muscular tunica (SMT) and the inner edge of the intima in each quadrant was measured, and the mean value for these 4 measurements was calculated (Fig. 3). Two independent blinded examiners assessed the reproducibility of the measurements.

\section{Immunohistochemistry}

\section{Immunohistochemical Staining Technique for TNF $\alpha$}

Paraffin sections were deparaffinized with xylene, hydrated with ethanol, and rinsed in $\mathrm{dH}_{2} \mathrm{O}$. Sections are placed in an antigen retrieval solution $(0.01 \mathrm{M}$ citrate buffer, $\mathrm{pH}$ 6.0) for 30 minutes in a microwave oven at $100^{\circ} \mathrm{C}$. To block nonspecific binding of

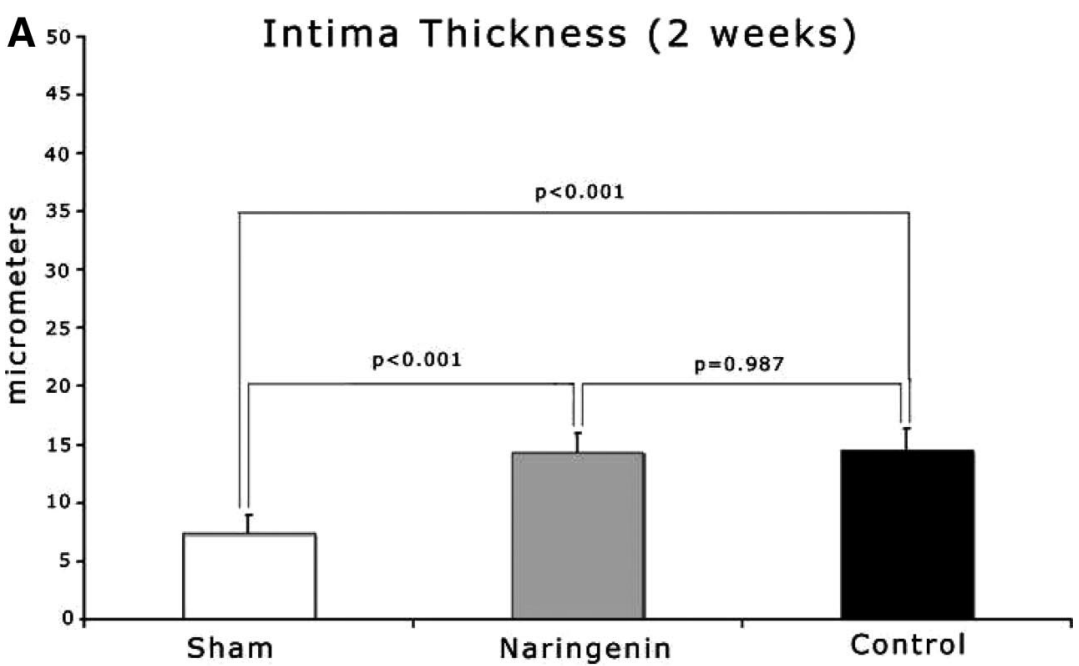

B

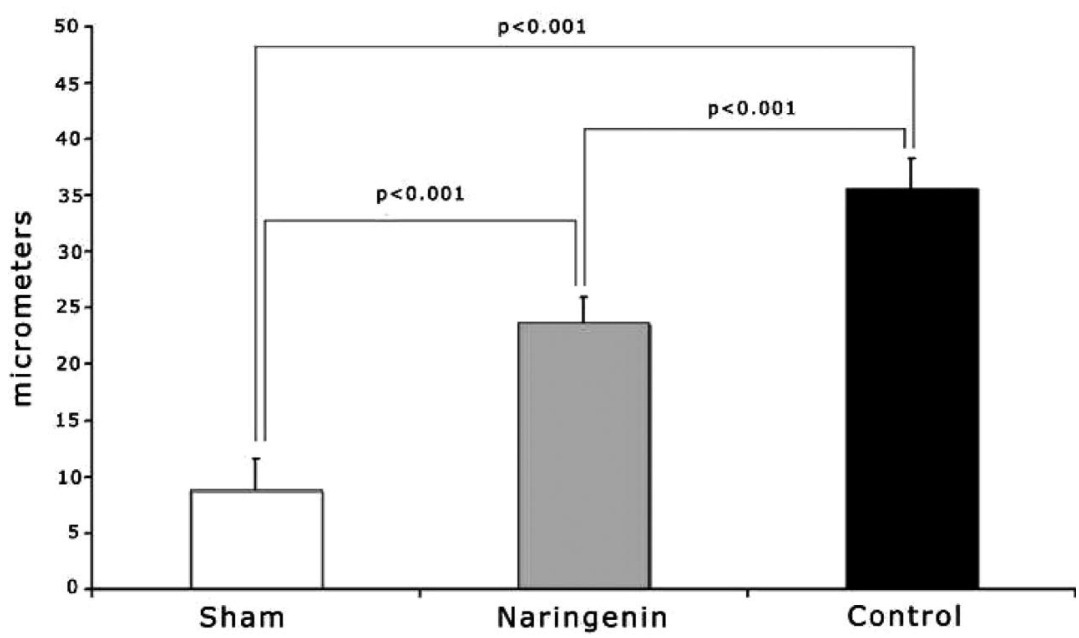

FIGURE 5. Effect of naringenin on intimal thickness at 2 (A) and 4 (B) weeks, the distance between the inner intimal surface to the internal elastic lamina. Values are expressed as mean \pm SEM $* P<0.05$ experiment groups compared with each other. 
immunoglobulin $10 \%$ normal horse serum-blocking solution is applied for 20 minutes in room temperature (RT). We incubated the sections in mouse anti-TNF $\alpha$ (MP-390, Endogen) diluted 1:150 for 1 hour at room temperature. The sections are rinsed, incubated first in peroxidase blocking solution for 10 minutes, and than biotinylated horse antimouse IgG for 30 minutes at room temperature. We used preformed Avidin: Biotinylated enzyme Complex (VECTASTAIN ABC kit-Vector Laboratories, Burlingame, CA) as the detection reagent, for 30 minutes. Sections are incubated in DAB peroxidase substrate solution (5 minutes) and counterstained with Gill's hematoxylin solution. Following dehydration with ethanol, and cleansing with xylene, sections are cover slipped with permanent mounting medium.

\section{Immunohistochemical Staining Technique for Ki-67}

Paraffin sections were deparaffinized with xylene, hydrated with ethanol, and rinsed in $\mathrm{dH}_{2} \mathrm{O}$. Sections are placed in an antigen retrieval solution $(0.01 \mathrm{M}$ citrate buffer, $\mathrm{pH} 6.0)$ for 30 minutes in a microwave oven at $100^{\circ} \mathrm{C}$. Normal goat serum blocking solution was used to block nonspecific binding of Ig. Rabbit antihuman Ki67 monoclonal antibody (VP-RM04, Vector Laboratories) in 1:200 dilution for 60 minutes in RT, was used as the primary antibody. After quenching of endogenous peroxide, sections were incubated in biotinylated Goat antirabbit IgG. ABC kit was used as the detection reagent; sections were incubated in $\mathrm{DAB}$ solution and counterstained with Gill's hematoxylin solution. The slides were dehydrated with ethanol, cleansed with xylene and cover slipped with permanent mounting medium.

\section{Immunohistochemical Staining Technique for PDGF-BB}

To determine the levels of PDGF-BB, we used goat antirhPDGF-BB antibody (AF-220-NA, R\&D Systems, Minneapolis, MN) and a secondary antigoat IgG antibody. Slides were deparaffinized and substrate retrieved by boiling in $\mathrm{pH} 6.0$ citrate buffer. Sections were blocked with $10 \%$ goat serum for 20 minutes and then incubated with primary antibody in 1:150 dilution at RT. The slides were then rinsed and incubated with the secondary antigoat antibody for 40 minutes. ABC kit was used as the detection reagent; sections were incubated in $\mathrm{DAB}$ solution and counterstained with Gill's hematoxylin solution. The slides were dehydrated with ethanol, cleansed with xylene and cover slipped with permanent mounting medium.

\section{Image Capture and Analyses}

Sections were observed under Axioplan 2 Imaging microscope (Carl Zeiss). The images were captured by a camera attached to the microscope (Axiocam, Carl Zeiss) and transferred to a computer, using software AxioVision Version 3.1 (Carl Zeiss). To measure the thickness of the intima, cross sectional photomicrographs of interposed graft (hematoxylin and eosin staining) at $\times 100$ magnification were captured. To quantify the amount and the distribution of PDGF-BB, TNF $\alpha$, and Ki67 2 randomly chosen fields at $400 \times$ magnification were captured.

Firstly all slides were investigated to examine the quality of the brown immunopositive staining for PDGF-BB, and blue immunopositive staining for TNF-alpha, as well as typical brown nuclear staining for Ki-67; the pixel threshold values could be determined by visual inspection. To overcome possible assessment bias with this technique, a double-blind design was performed. At $\times 400$ magnification 2 randomly chosen areas were sampled and captured, this time to avoid allocation bias.

To assess the levels of PDGF-BB or TNF $\alpha$ activity, tissue sections were analyzed and measured using Image-Pro Plus Ver.4.5.1. Software (Media Cybernetics, Silver Spring, MD).
Briefly, this software allows structures to be selected on the basis of pixel intensity values in a given color channel. Using the freeform drawing tool in Image-Pro Plus, we selected the areas stained with IHC method as the areas-of-interest (AOI). A color file was created that exactly selected the hue, saturation, and intensity (color coding) which corresponds to the to the expression level of the measured antigen. Hue, saturation, and intensity color coding was chosen because this method specifies color by hue, excludes features that are too light or dark by intensity, but at the same time allows measurement of the amount of the specified color by saturation. Areas of interest were enclosed using the AOI tool and then thresholded, using Measure|Count/ Size . . . Manual Intensity Range selection tool. The results were reported as "percent area positively stained" (ratio between the stained area and the AOI).

For the assessments for Ki67, the sections were analyzed using software AxioVision Version 3.1 (Carl Zeiss). The cells were judged to be positive when their nuclei contained dark brown reaction products. The Ki67 labeling index (Ki67 LI) was calculated as the percentage of Ki67 positive cells among the total number of cells in the region of interest. ${ }^{25}$

\section{Statistical Analysis}

Data was processed using SPSS Ver.11.5 for Windows (SPSS Inc, Chicago, IL). One-way ANOVA was performed to compare groups with different treatments; post hoc analysis was done with Tukey test, Dunnett $t$ test, or Games-Howell procedure depending on the homogeneity of variances. The cut-off for significance was $P<0.05$.

\section{RESULTS}

Vein graft intimal thickening follows a specific time course. By the end of second week, initially denuded endothelial surface is completely recovered with endothelial cells. After this time intimal thickening is exaggerated. ${ }^{26}$ During the next 2 weeks, the increase in wall mass is exponential with associated smooth muscle cell prolif-
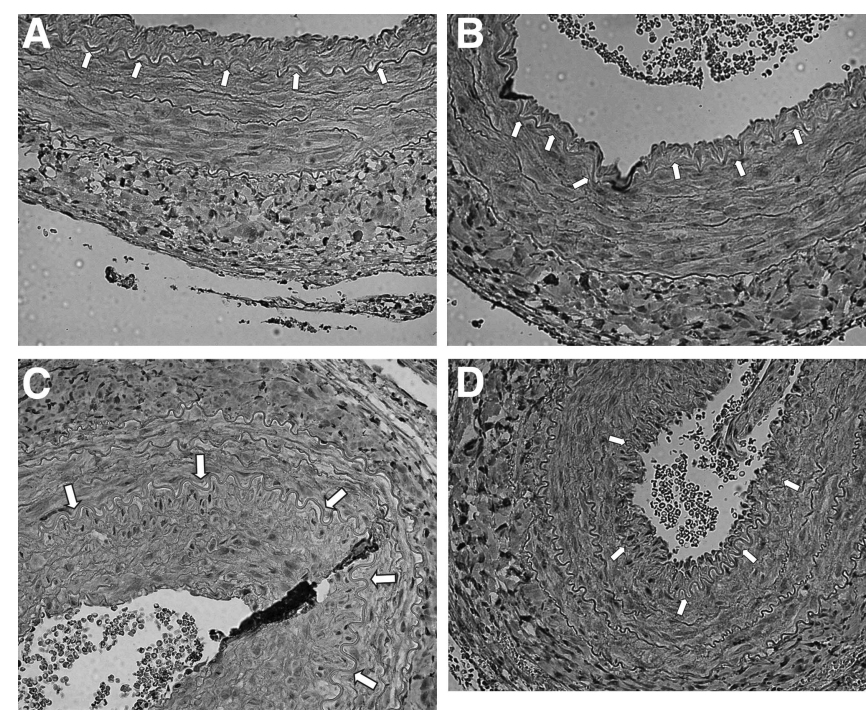

FIGURE 6. Photomicrographs showing representative cross sections of interpositional vein grafts. (Immunohistochemical staining for PDGF-BB). A, Control group at 2 weeks. B, Naringenin group at 2 weeks. C, Control group at 4 weeks. D, Naringenin group at 4 weeks. White arrows indicate internal elastic membrane. Original magnification $\times 400$. 
eration and accumulation. ${ }^{26}$ Based on this time course we evaluated intimal thickness, levels of PDGF-BB, TNF $\alpha$ activity, and $\mathrm{Ki} 67$ labeling at 2 weeks and 4 weeks.

In the follow up period, 1 rat from the naringenin treated group, and 1 rat from the control group died. During the harvesting procedure vein grafts of 2 rats from control group, and one from the experimental group was detected to have no patency; these 3 rats were excluded from the study.

\section{Effect of Naringenin on Neointimal Hyperplasia by Morphometric Analysis}

At 2 weeks, intimal thickness was lower in the naringenin treated experiment group but the difference was not statistically significant $(14.35 \pm 1.6$ vs. $14.48 \pm 1.9 \mu \mathrm{m}$ in control group, $P=$ 0.987) (Figs. 4, 5A). Both the experimental and control groups exhibited statistically significant intimal thickness, compared with Sham group ([7.35 \pm 1.5 vs. $14.35 \pm 1.6 \mu \mathrm{m}$ in experimental group, $P<0.001]$ and $[7.35 \pm 1.5$ vs. $14.48 \pm 1.9 \mu \mathrm{m}$ in control group, $P<0.001]$ ).

At 4 weeks, the experimental group was found to have a reduced intimal thickness compared with controls, $(23.69 \pm 2.3$ vs. $35.64 \pm 2.6 \mu \mathrm{m}$ in control group, $P<0.001$ ) (Fig. 5B). Both the experimental $(23.69 \pm 2.3$ vs. $8.78 \pm 2.8 \mu \mathrm{m}$ in Sham group, $P<$
$0.001)$ and control $(35.64 \pm 2.6$ vs. $8.78 \pm 2.8 \mu \mathrm{m}$ in Sham group, $P<0.001)$ groups had increased intimal thickness when compared with Sham group (Fig. 5B).

\section{Effect of Naringenin on the Level of PDGF-BB}

At 2 weeks, the percentage of PDGF-BB labeled area in controls was significantly greater compared with the naringenin treated experimental group $(0.21 \% \pm 0.03 \%$ vs. $0.39 \% \pm 0.05 \%$ in controls, $P<0.001$ ) (Fig. 6). The percentage of PDGF-BB stained area both in experimental $(0.21 \% \pm 0.03 \%$ vs. $0.12 \% \pm 0.01 \%$ in Sham, $P<0.001)$ and control $(0.39 \% \pm 0.05 \%$ vs. $0.12 \% \pm 0.01 \%$ in Sham, $P<0.001)$ groups was significantly higher than Sham group (Fig. 7A).

At 4 weeks, the immunohistochemically labeled area for PDGF-BB was higher in the control group when compared with the experimental group $(0.57 \% \pm 0.09 \%$ vs. $0.25 \% \pm 0.02 \%$ in experimental group, $P<0.001)$. Sham group had significantly lower positively labeled percent area with PDGF-BB than both experiment and control groups $([0.09 \% \pm 0.03 \%$ vs. $0.25 \% \pm 0.02 \%$, in experimental group, $P<0.001],[0.09 \% \pm 0.03 \%$ vs. $0.57 \% \pm$ $0.09 \%$, in control group, $P<0.001]$ (Fig. 7B).

\section{A $_{1.00 \%} \quad$ PDGF-BB Activity (2 Weeks)}
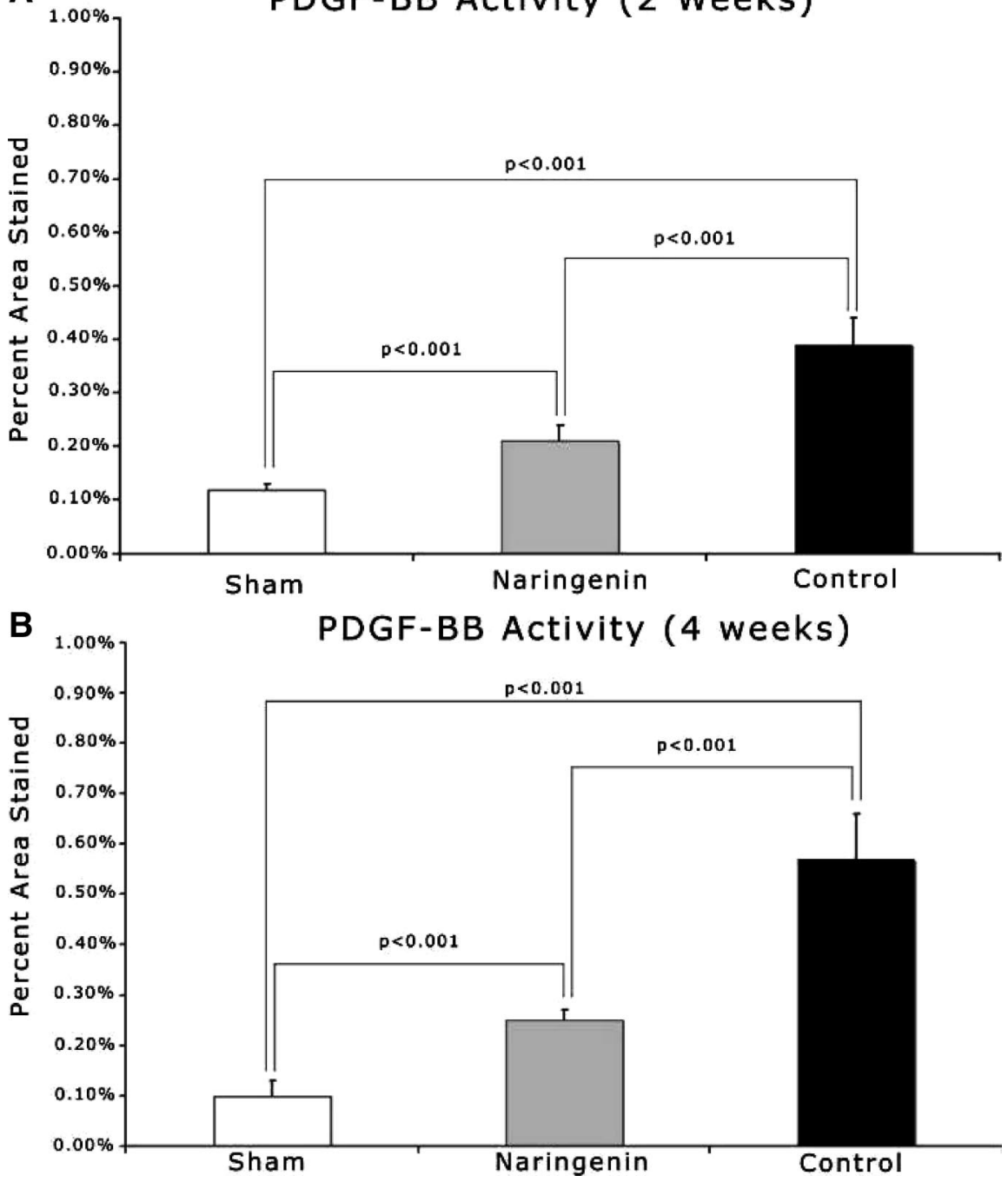

FIGURE 7. Bar graphs for the PDGF activity at 2 (A) and 4 (B) weeks. PDGF activity is expressed as a percentage of the area positive for PDGF stain/total area of interest (AOI). Values are expressed as mean \pm SEM ${ }^{*} P<0.05$ experiment groups compared with each other. 

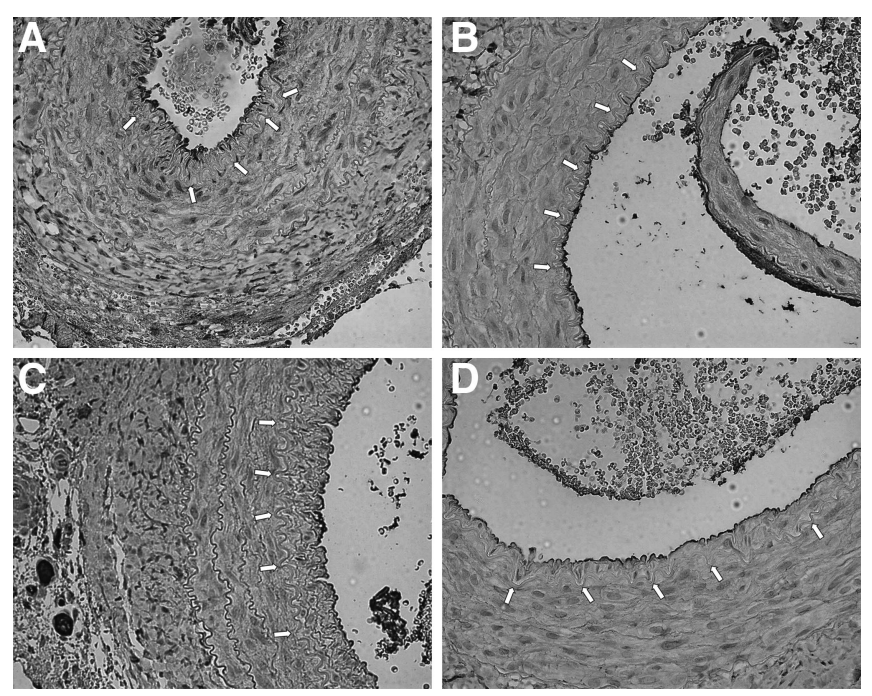

FIGURE 8. Photomicrographs showing representative cross sections of interpositional vein grafts. (Immunohistochemical staining for TNF alpha). A, Control group at 2 weeks. B, Naringenin group at 2 weeks. C, Control group at 4 weeks. D, Naringenin group at 4 weeks. White arrows indicate internal elastic membrane. Original magnification $\times 400$.

\section{Effect of Naringenin on the Level of TNF $\alpha$}

$\mathrm{TNF} \alpha$ levels were lower in experimental group when compared with control group at 2 weeks $(21.2 \% \pm 0.8 \%$ vs. $36.04 \% \pm$ $1.8 \%$, in control, $P<0.001$ ) (Fig. 8). TNF $\alpha$ levels in Sham group $(12.5 \% \pm 1.6 \%)$ were lower than both experimental $(P<0.001)$ and control $(P<0.001)$ groups (Fig. 9A).

At 4 weeks, percent area labeled for $\mathrm{TNF} \alpha$, in control $(45.02 \% \pm 2.8 \%)$ group was significantly higher when compared with experimental $(25.5 \% \pm 1.8 \%)$ group $(P<0.001)$. The percent area labeled in Sham group $(11.1 \% \pm 0.9 \%)$ was significantly lower than both experimental $(P<0.001)$ and control $(P<0.001)$ groups. (Fig. 9B).

\section{Effect of Naringenin on the Ki67 Labeling Index}

At 2 weeks, the control group exhibited significantly higher Ki67 LI $(18.7 \% \pm 3.7 \%)$ when compared with experiment $(13.9 \% \pm 2.8 \%)$ group $(P=0.030)$ (Fig. 10). Sham group's Ki67 LI $(6.4 \% \pm 1.0 \%)$ was significantly lower than both experimental $(P<0.001)$ and control $(P<0.001)$ groups (Fig. 11A).

At 4 weeks, the experimental group had a significantly lower Ki67 LI (17.5\% $\pm 2.3 \%)$ when compared with control $(31.1 \% \pm$ $4.7 \%)$ group $(P<0.001)$. The difference in Sham group Ki67 LI $(7.04 \% \pm 0.8 \%)$ and both control $(P<0.001)$ and experimental $(P<0.001)$ were statistically significant (Fig. 11B).

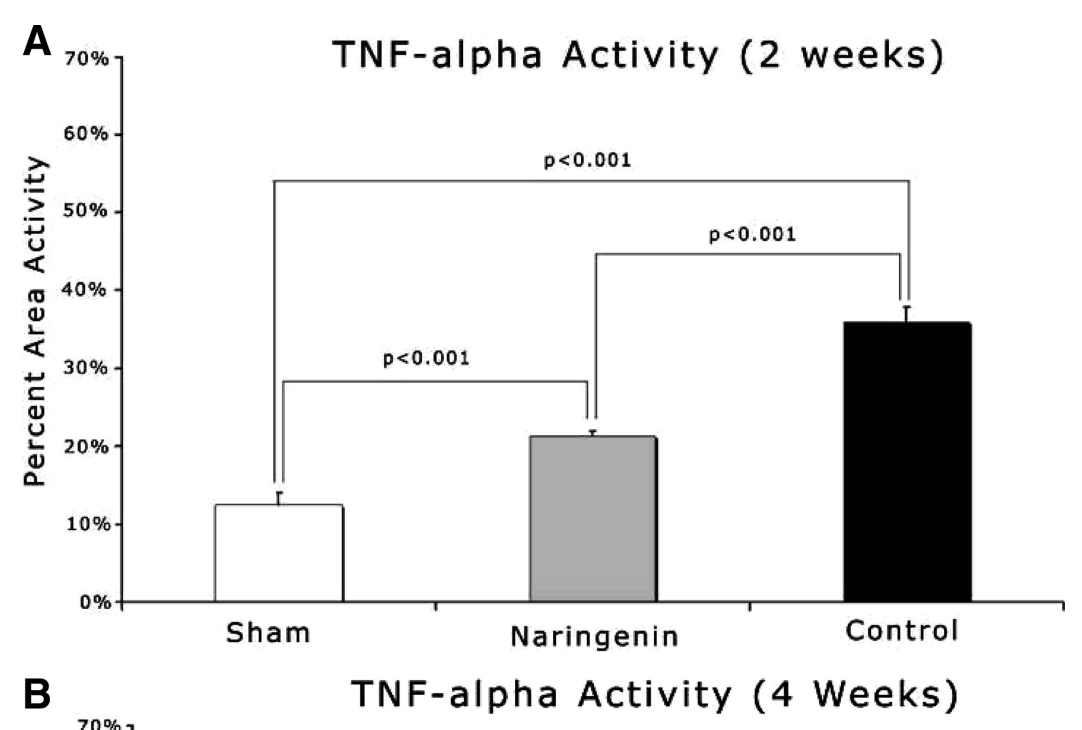

FIGURE 9. Bar graphs for the TNF-alpha activity at $2(\mathrm{~A})$ and 4 (B) weeks. TNF-alpha activity is expressed as a percentage of the area positive for TNF-alpha stain/total area of interest (AOI). Values are expressed as mean \pm SEM $* P<0.05$ experiment groups compared with each other.

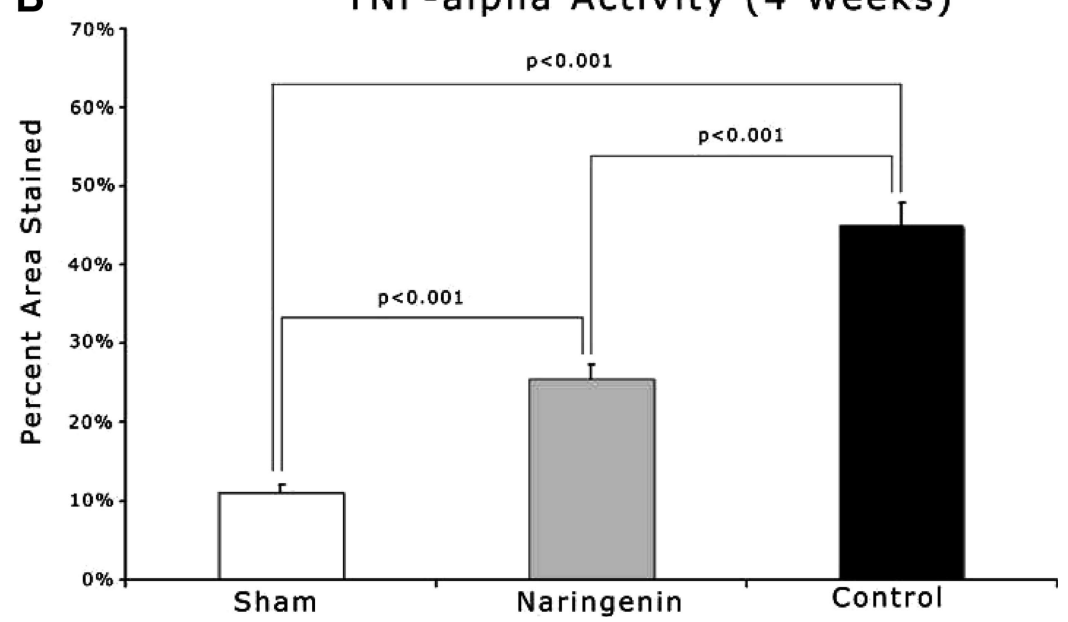



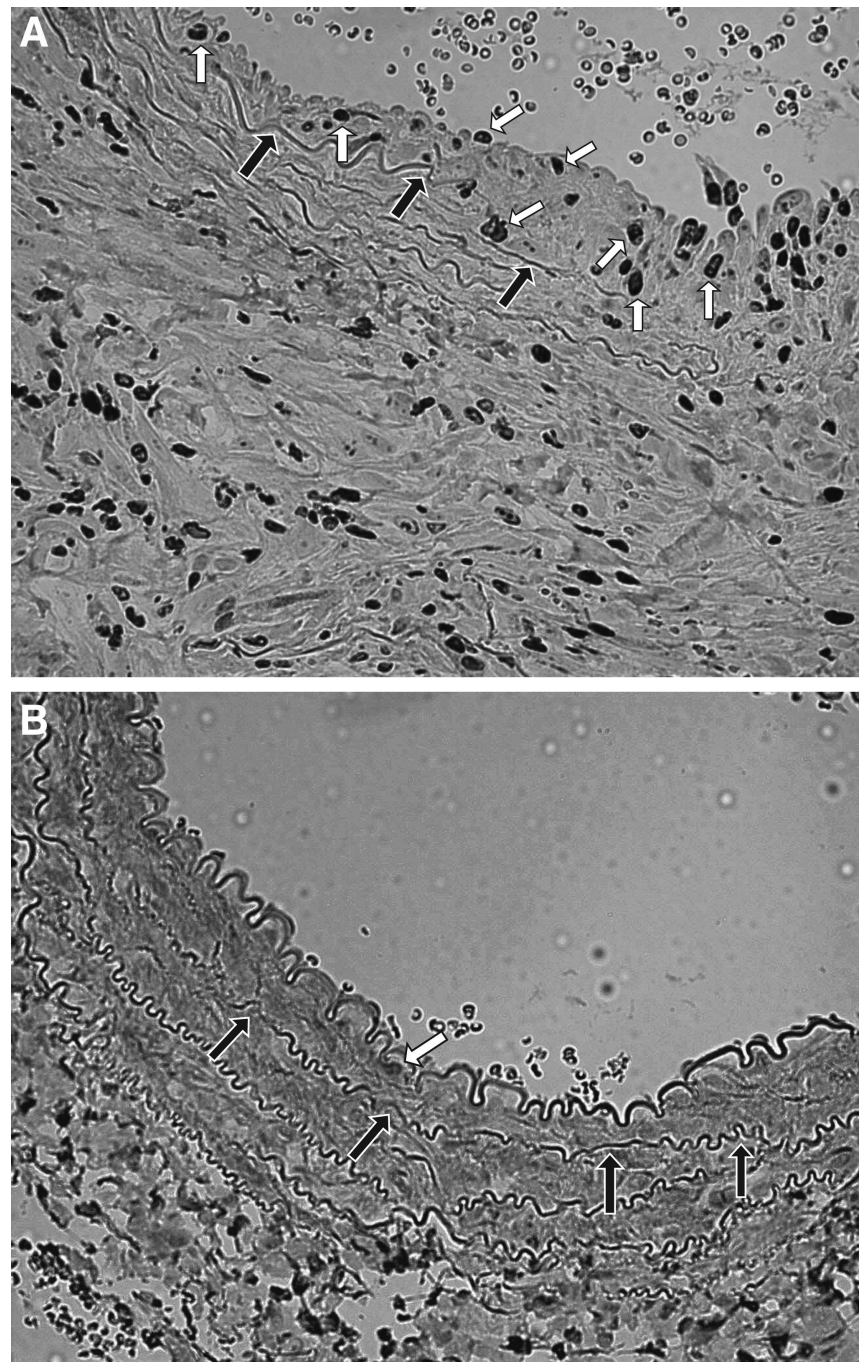

FIGURE 10. Photomicrographs showing representative cross sections of interpositional vein grafts. (Immunohistochemical staining for Ki67). A, Control group at 4 weeks. B, Naringenin group at 4 weeks. White arrows indicate cells that are positive for Ki67 stain; black arrows indicate internal elastic membrane. Original magnification $\times 400$.

\section{DISCUSSION}

New information regarding the physiological timeline of neointimal hyperplasia allows for further understanding about the specific time and events following vascular injury. Therefore, it becomes much easier to study potential interventions to minimize the microscopic damage and thus increase not only graft patency but patient vitality.

The presence of endothelial cells at the site of damage likely plays a large role in the injury response mechanism. Because it is at the interface between the blood and the vessel wall, endothelium is a potential regulator of arterial wall homeostasis. Endothelial cells could regulate the underlying cellular growth and regression, ${ }^{27-30}$ as they can secrete factors that affect smooth muscle proliferation, growth, and migration. ${ }^{27,31}$ These factors are likely present after vascular injury implicating them as not only a marker but a stimulator of neointimal hyperplasia.
Arterial reconstruction is associated with 2 types of arterial injury. The first type is mechanical injury of the native vessel due to dissection of the artery, suture, endarterectomy, thrombectomy, or luminal angioplasty. The second type of injury is associated with the implantation of nonarterial structures such as autologous vein graft, synthetic graft, or any alloplastic material in contact with the arterial blood flow such as a stent. In this second type of injury, a healing response is induced to optimize the relationship between the newly shaped arterial conduit, the surrounding tissues on the adventitial side, ${ }^{32}$ and the blood flow on the luminal side. ${ }^{33}$ As part of the response, predominantly smooth muscle cells proliferate, ${ }^{34}$ extracellular matrix is synthesized and deposited, and graft extrinsic cells are recruited into the arterializing graft ${ }^{35}$; forming neointima composed of smooth muscle cells as well as collagen, elastin, and proteoglycans..$^{7,36-38}$

Furthermore, vein grafts in the arterial circulation develop intimal thickening, whereas this process does not occur in veins transposed to venous circulation. ${ }^{39}$ This suggests that hemodynamic stress is a major determinant in venous bypass structural changes. ${ }^{39}$ There is a time course in venous intimal thickening, described in a rabbit model, in which the external jugular vein is transplanted into the carotid artery. ${ }^{26}$ Initially platelets, microthrombi, and leukocytes adhere mostly to the anastomoses where the endothelium is denuded. In 2 weeks, the denuded surface is completely covered with new endothelial lining, as the intimal thickening starts to develop. The functional pathway of the endothelium allows for 2 potential points of intervention, the regulation of smooth muscle cell migration and smooth muscle cell proliferation. In this complex process, evidence of a supporting role for proinflammatory cytokines is emerging. ${ }^{40-42}$

In this study, naringenin proved to be an effective treatment in preventing neointimal hyperplasia. This ability to reduce hyperplasia was demonstrated at 4 weeks and not at 2 weeks. This evidence points to the likely effect of naringenin mainly revolving around the inhibition of smooth muscle cell proliferation rather than the early smooth muscle cell migration. This is further demonstrated in morphometric analysis of the intimal thickness (in 2 week groups, intimal thickness was lower in the naringenin treated experiment group but the difference was not statistically significant $[14.35 \pm 1.6$ vs. $14.48 \pm 1.9 \mu \mathrm{m}$ in control group, $P=0.987]$, but in 4 weeks the experimental group was found to have a reduced intimal thickness compared with controls, $[23.69 \pm 2.3$ vs. $35.64 \pm 2.6 \mu \mathrm{m}$ in control group, $P<0.001]$ ). To provide even further data about the functional mechanism of naringenin, future experiments could also include a group in which naringenin is given in the third week

The stimulatory effect of PDGF on vascular smooth muscle cells, especially 1 of 3 isoforms, PDGF-BB, is both migration and proliferation in vitro, and migration in vivo. ${ }^{43}$ Additionally, PDGF prevents programmed cell death (apoptosis) in endothelial cells, which might contribute to the increased number of cells in the intima. ${ }^{44}$ The effect of naringenin on PDGF-BB levels was statistically significant in reducing the presence of this marker at both 2 and 4 weeks. These results demonstrate the ability of naringenin to affect cellular migration and proliferation. The statistical significance of the difference between positively stained PDGF levels in the 2 groups grew from 2 to 4 weeks, indicating the continued effect of naringenin on smooth muscle cell migration and proliferation.

Another marker studied in this project was TNF $\alpha$. TNF $\alpha$ has multiple biologic effects, including induction of the expression of cell surface adhesion molecules, release of other inflammatory mediators (particularly IL-1 $\beta$ ) and induction of endothelial cell apoptosis. Accelerated functional endothelial recovery was possible following de-endothelialization, via neutralization of the effects of free TNF $\alpha$ by $\mathrm{TNF} \alpha$ soluble receptor (TNFsr) ${ }^{45}$ suggesting a 


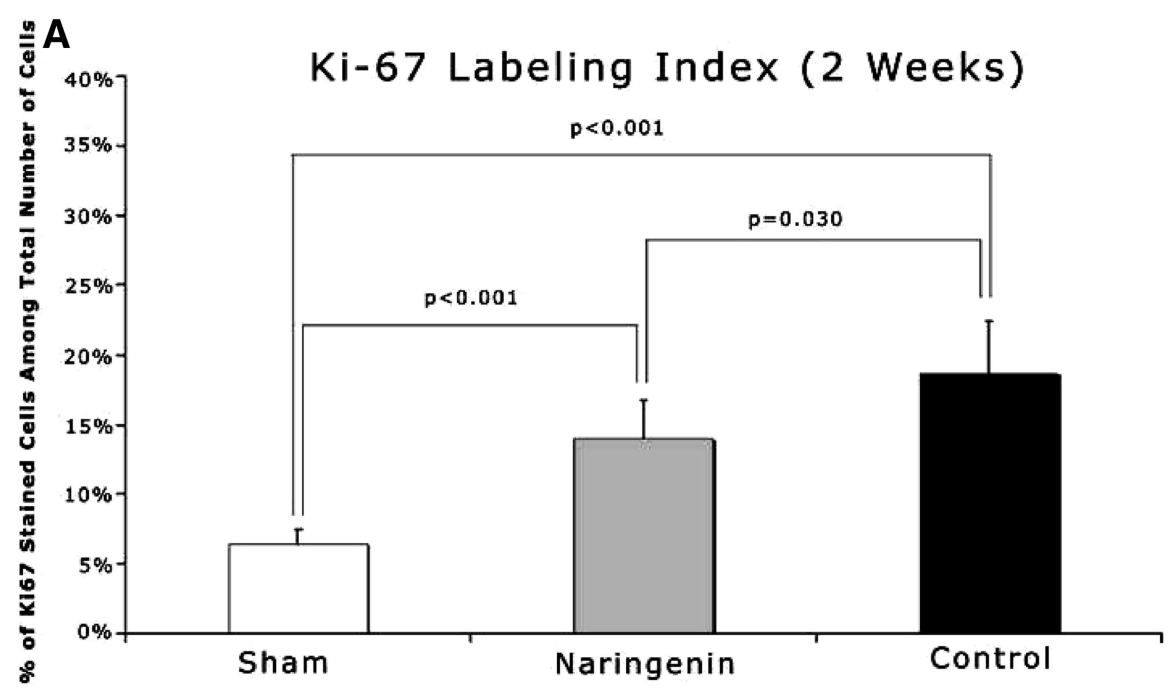

FIGURE 11. Bar graphs for the Ki67 labeling index (Ki67 LI) at 2 (A) and 4 (B) weeks. Ki67 LI was calculated as the percentage of Ki67 positive cells among the total number of cells in the region of interest. Values are expressed as mean \pm SEM $* P<0.05$ experiment groups compared with each other.
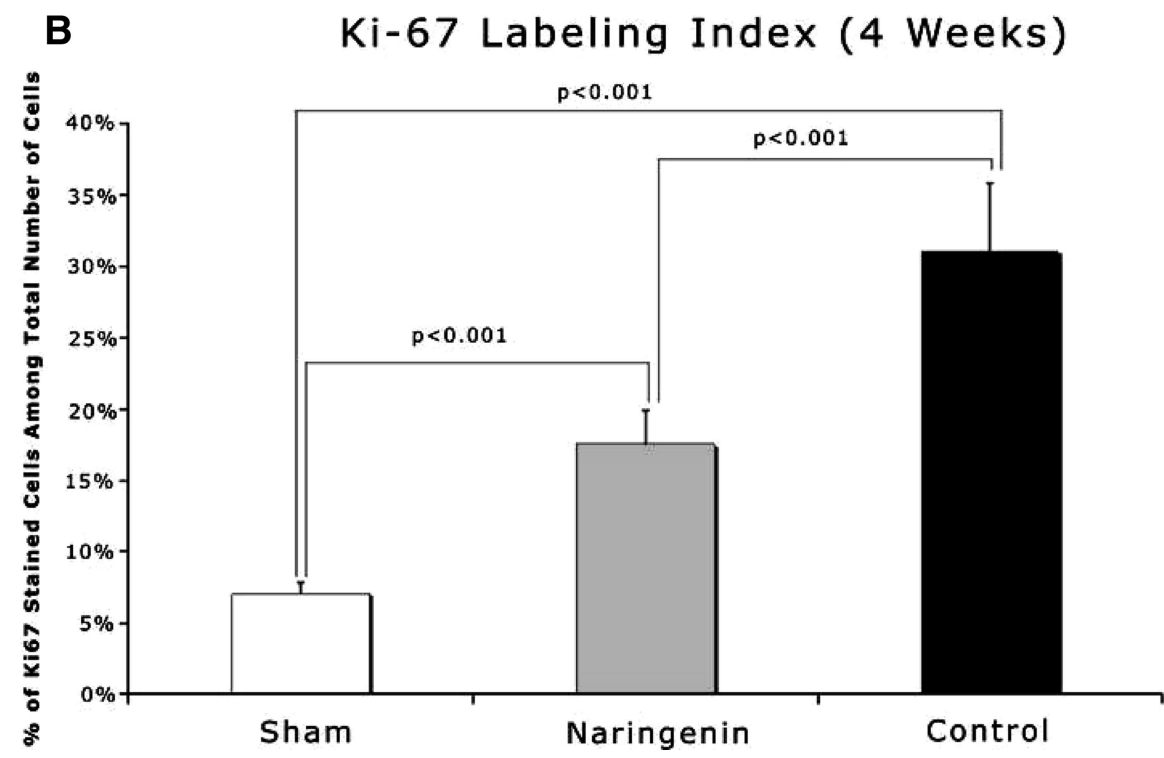

deleterious role for this cytokine on endothelial cell regrowth. Inhibition of either the receptor or the release of TNF $\alpha$ may prove advantageous in the prevention of NIH. The presence of naringenin, in this study, demonstrated just this ability. At both 2 and 4 weeks, the presence of naringenin significantly reduced the presence of stained TNF $\alpha$. Once again, the difference increased as time progressed indicating the affect is likely due to the inhibition of proliferation rather than migration.

Finally, this study looked at the affect of naringenin on cellular proliferation. Ki67 is a very important method in detecting the proliferation of cells. In fact, the levels of Ki7LI are directly proportional with the staging/prognosis of cancer, due to cancer's higher, more aggressive proliferation. In this study, Ki67 is used as a reliable indicator of smooth muscle cell proliferation in the intima. As with both of the previously mentioned indicators, levels of Ki67 were significant at both 2 weeks and 4 weeks. The increase in the difference and significance, along with the known physiology of Ki67, demonstrate the ability of naringenin to decrease cellular proliferation.

The flavanoid, Naringenin, demonstrates the ability to act as a potent inhibitor of neointimal hyperplasia as shown in all aspects of the results. In nearly all portions of this study, Naringenin was able to significantly reduce hyperplasia at both 2 and 4 weeks. However, it must be noted that there was no thickness difference at 2 weeks. This speaks, once again, to the likely mechanism of Naringenin with respect to NIH. It will be important for future research to delve into the exact mechanism of Naringenin and its actions against NIH. Naringenin has demonstrated in this study its effectiveness in reducing the hyperplasia response due to vascular injury. More research is certainly needed to completely understand the actions of this drug along with its interaction with other NIH inhibitors. It must also be noted that side effects and safety of Naringenin was not observed in this research, as it was necessary to first ascertain the potential benefits and potential mechanism of this drug. Further research in this area is also necessary.

The effectiveness of Naringenin in reducing $\mathrm{NIH}$ was clearly demonstrated in this study. Flavinoids such as this, represent a potent chemical available for the reduction of this dangerous response. Though the exact mechanism of Naringenin is not completely understood, the likely inhibition of smooth muscle cell proliferation provides an effective tool in the prevention of NIH. 


\section{REFERENCES}

1. Allaire E, Clowes AW. Endothelial cell injury in cardiovascular surgery: the intimal hyperplastic response. Ann Thorac Surg. 1997;63:582-591.

2. Wissler RW, Hiltscher L, Oinuma T. The lesions of atherosclerosis in the young. In: Fuster V, Ross R, Topol EJ, eds. Atherosclerosis and Coronary Artery Disease. Philadelphia: Lippincott-Raven; 1996:475-489.

3. Stary HC. The histological classification of atherosclerotic lesions in human coronary arteries. In: Fuster V, Ross R, Topol EJ, eds. Atherosclerosis and Coronary Artery Disease. Philadelphia: Lippincott-Raven; 1996:463-474

4. Falk E, Shah PK, Fuster V. Pathogenesis of plaque disruption. In: Fuster V, Ross R, Topol EJ, eds. Atherosclerosis and Coronary Artery Disease. Philadelphia: Lippincott-Raven; 1996:491-507.

5. Booyse FM, Osikowicz G, Quarfoot AJ. Effects of chronic oral consumption of nicotine on the rabbit aortic endothelium. Am J Pathol. 1981;102:229-238.

6. Boutet M, Bazin M, Turcotte H, et al. Effects of cigarette smoke on rat thoracic aorta. Artery. 1980;7:56-72.

7. Salonen JT, Yla-Herttuala S, Yamamoto R, et al. Autoantibody against oxidised LDL and progression of carotid atherosclerosis. Lancet. 1992;339: 883-887.

8. Fuster W, Bowie EJ, Lewis JC, et al. Resistance to arteriosclerosis in pigs with von Willebrand's disease. Spontaneous and high cholesterol diet-induced arteriosclerosis. J Clin Invest. 1978;61:722-730.

9. Rectenwald JE, Moldawer LL, Huber TS, et al. Direct evidence for cytokine involvement in neointimal hyperplasia. Circulation. 2000;102:1697-1702.

10. Zimmerman MA, Selzman CH, Reznikov LL, et al. Lack of TNF-alpha attenuates intimal hyperplasia after mouse carotid artery injury. Am J Physiol Regul Integr Comp Physiol. 2002;283:R505-R512.

11. Andreakos ET, Foxwell BM, Brennan FM, et al. Cytokines and anti-cytokine biologicals in autoimmunity: present and future. Cytokine Growth Factor Rev. 2002;13:299-313.

12. Moriera R, Carlos I, Vilegas V. Release of intermediate reactive hydrogen peroxide by macrophage cells activated by natural products. Biol Pharm Bull. 2001;24:201-204.

13. Yuting $\mathrm{C}$, Rongliang $\mathrm{C}$, Zhongjian J, et al. Flavinoids as superoxide scavengers and antioxidants. Free Radic Biol Med. 1990;9:19-21.

14. Manthey JA. Biological properties of flavonoids pertaining to inflammation. Microcirculation. 2000;7:S29-S34.

15. Wadsworth T, Dennis R. Effects of the wine polyphenolics quercetin and resveratrol on pro-inflammatory cytokine expression in RAW264.7 macrophages. Biochem Pharmacol. 1999;57.

16. Cho JY, Kim PS, Park J, et al. Inhibitor of tumor necrosis factor-alpha production in lipopolysaccharide-stimulated RAW264.7 cells from Amorpha fruticosa. J Ethnopharmacol. 2000;70:127-133.

17. Lyu SY, Park WB. Production of cytokine and NO by RAW 264.7 macrophages and PBMC in vitro incubation with flavonoids. Arch Pharm Res. $2005 ; 28: 573-581$

18. Herath HM, Takano-Ishikawa Y Yamaki K. Inhibitory effect of some flavonoids on tumor necrosis factor-alpha production in lipopolysaccharidestimulated mouse macrophage cell line J774.1. J Med Food. 2003;6:365-370.

19. Liu X, Wang W, Hu H, et al. Smad3 specific inhibitor, naringenin, decreases the expression of extracellular matrix induced by TGF-betal in cultured rat hepatic stellate cells. Pharm Res. 2006;23:82-89.

20. Luscher TF. The endothelium and cardiovascular disease-a complex relation. N Engl J Med. 1994;330:1081-1083.

21. Chobanian AV. 1989 Corcoran lecture: adaptive and maladaptive responses of the arterial wall to hypertension. Hypertension. 1990;15:666-674.

22. Panza JA, Quyyumi AA, Brush JE Jr, et al. Abnormal endothelium-dependent vascular relaxation in patients with essential hypertension. $N$ Engl J Med. 1990;323:22-27.

23. Ackland RD. Microsurgery. A Practice Manual. St. Louis, MO: Mosby; 1980
24. Zhang S, Qin C, Safe SH. Flavonoids as aryl hydrocarbon receptor agonists antagonists: effects of structure and cell context. Environ Health Perspect. 2003;111:1877-1882.

25. Kawakubo H, Ozawa S, Ando N, et al. Alterations of p53, cyclin D1 and pRB expression in the carcinogenesis of esophageal squamous cell carcinoma. Oncol Rep. 2005;14:1453-1459.

26. Gotlieb AI, Langille BL. The role of rheology in atherosclerotic coronary artery disease. In: Ross R, Topol EJ, Fuster V, eds. Atherosclerosis and Coronary Artery Disease. Philadelphia: Lippincott-Raven: 1996:595-606.

27. Clinton SK, Underwood R, Hayes L, et al. Macrophage colony-stimulating factor gene expression in vascular cells and in experimental and human atherosclerosis. Am J Pathol. 1992;140:301-316.

28. Rosenfeld ME, Yla-Herttuala S, Lipton BA, et al. Macrophage colonystimulating factor mRNA and protein in atherosclerotic lesions of rabbits and humans. Am J Pathol. 1992;140:291-300.

29. Cushing SD, Berliner JA, Valente AJ, et al. Minimally modified low density lipoprotein induces monocyte chemotactic protein 1 in human endothelia cells and smooth muscle cells. Proc Natl Acad Sci USA. 1990;87:5134-5138.

30. Dzau VJ, Gibbons GH, Cooke JP, et al. Vascular biology and medicine in the 1990s: scope, concepts, potentials, and perspectives. Circulation. 1993;87: 705-719

31. Matsumoto A, Naito M, Itakura $\mathrm{H}$, et al. Human macrophage scavenger receptors: primary structure, expression, and localization in atherosclerotic lesions. Proc Natl Acad Sci U S A. 1990;87:9133-9137.

32. Assoian RK, Fleurdelys BE, Stevenson HC, et al. Expression and secretion of type beta transforming growth factor by activated human macrophages. Proc Natl Acad Sci U S A. 1987;84:6020-6024.

33. Raines EW, Dower SK, Ross R. Interleukin-1 mitogenic activity for fibroblasts and smooth muscle cells is due to PDGF-AA. Science. 1989;243:393396.

34. Peppel K, Zhang L, Huynh TT, et al. Overexpression of G protein-coupled receptor kinase-2 in smooth muscle cells reduces neointimal hyperplasia. J Mol Cell Cardiol. 2002;34:1399-1409.

35. Zhang L, Freedman NJ, Brian L, et al. Graft-extrinsic cells predominate in vein graft arterialization. Arterioscler Thromb Vasc Biol. 2004;24:470-476.

36. Gay CG, Winkles JA. Interleukin 1 regulates heparin-binding growth factor 2 gene expression in vascular smooth muscle cells. Proc Natl Acad Sci U S A 1991;88:296-300

37. Galis ZS, Sukhova GK, Kranzhofer R, et al. Macrophage foam cells from experimental atheroma constitutively produce matrix-degrading proteinases. Proc Natl Acad Sci U S A. 1995;92:402-406.

38. Lendon CL, Davies MJ, Born GV, et al. Atherosclerotic plaque caps are locally weakened when macrophages density is increased. Atherosclerosis. 1991;87:87-90.

39. Brody WR, Angeli WW, Kosek JC. Histologic fate of the venous coronary artery bypass in dogs. Am J Pathol. 1972;66:111-130.

40. Faries PL, Marin ML, Veith FJ, et al. Immunolocalization and temporal distribution of cytokine expression during the development of vein graft intimal hyperplasia in an experimental model. J Vasc Surg. 1996;24:463471.

41. Crook MF, Newby AC, Southgate KM. Expression of intercellular adhesion molecules in human saphenous veins: effects of inflammatory cytokines and neointima formation in culture. Atherosclerosis. 2000;150:33-41.

42. Sterpetti AV, Cucina A, Lepidi S, et al. Formation of myointimal hyperplasia and cytokine production in experimental vein grafts. Surgery. 1998;123:461469

43. Koyama N, Hart CE, Clowes AW. Different functions of the platelet-derived growth factor-alpha and -beta receptors for the migration and proliferation of cultured baboon smooth muscle cells. Circ Res. 1994;75:682-691.

44. Corson MA, Berk BC. Growth factors and the vessel wall. Heart Dis Stroke 1993;2:166-170

45. Krasinski K, Spyridopoulos I, Kearney M, et al. In vivo blockade of tumor necrosis factor-alpha accelerates functional endothelial recovery after balloon angioplasty. Circulation. 2001;104:1754-1756. 